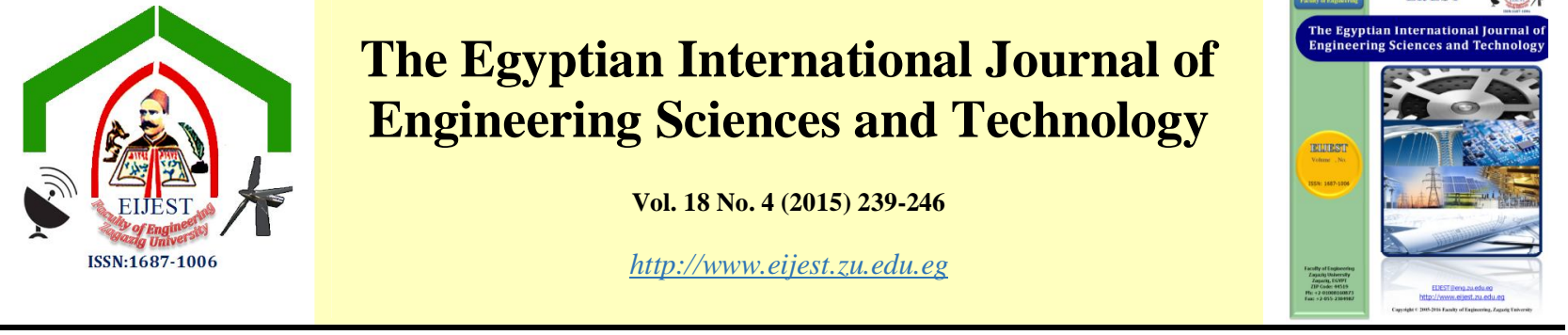

\title{
Effect of Region Subdividing on Water and Salt Balance Evaluation in Eastern Nile Delta
}

\author{
Osama K. Saleh ${ }^{\mathrm{a}}$, Maha R. Fahmy ${ }^{\mathrm{a}}$, Walaa Y. El Nashar ${ }^{\mathrm{a}}$ and Amgad H. Khorshed ${ }^{\mathrm{b}}$
}

${ }^{a}$ Department of Water and Water Structures, Zagazig University, Zagazig, Egypt

${ }^{\mathrm{b}}$ Irrigation Sector, Ministry of Water Resources and Irrigations (MWRI),Cairo, Egypt

\begin{tabular}{l}
\hline A R T I C L E I N F O \\
\hline Article history: \\
Received 20 Aug. 2015 \\
Received in revised form \\
/ / 2015 \\
Accepted / / 2015 \\
Available online / / \\
2015 \\
\hline
\end{tabular}

Keywords:

Water balance

Salt balance

Water use efficiency

\begin{abstract}
A B S T R A C T
The main objectives of the study aim at optimal exploitation of the water resources in Eastern Nile Delta region. Until now, the Ministry of Water Resources and Irrigation (MWRI) is managing water resources and the irrigation system by itself with high input of staff and high capital investment. The mission of MWRI is to ensure that Egypt's water resources are developed, allocated, used and preserved in a manner which is sustainable, equitable and efficient. The research work evaluated the water balance, the salt balance, the water quality and the management plans in the study area from August 2000 to July 2010, also, attempted a new water management plan. In this paper, the water and salt balance first executed for the Eastern Nile Delta region (ENDR). To evaluate the effect of subdividing process on water and salt balance in the region, the Eastern Nile Delta region divided into two parts according to the irrigation and drainage systems. The first one is Manzala Irrigation and Drainage System (MIDS), the second is Ismailia Irrigation and Drainage System(IIDS). Water and salt balances results showed better and stable water management policies in IIDS with water supply followed evapotranspiration (ET) demands, fairly stable narrow range water use efficiency and salt leaching process. At the contrary, ENDR affected by MIDS, both water balances results showed poor follow of ET demands by water supply, wider range of water use efficiency and adding extra salt loads process in the salt balances boundaries. The results showed that the smaller are the area, the more accurate are the water and salt balance evaluations. Also, the results of all the water and salt balances didn't comply with MWRI mission.
\end{abstract}

\section{Introduction:}

The availability of water resources in Egypt is limited and network of canals and open drains is very complicated. A large quantities of water lost due to poor awareness of farmers about the importance of optimal use of water. The complexity of water demands requires understanding of our water sources and water destinations. It is only with a good water balance in hand that we can make good long-term decisions. In the Eastern Nile Delta, the rapid increase of water demand with time, the wasteful irrigation practice at the head of the tertiary canals leaves users at the tail end of the canals with inadequate fresh water to use. Polluted open drains located at the tail ends of irrigation canals offer the farmers an available continuous water supply. This caused illegal use of drainage water in irrigation (figure 1) by pumping highly polluted water from the open drains (Khorshed,2010). 

At the same time, there is no effective way to reduce this illegal irrigation with polluted water as long as farmers think that there is no sufficient fresh water for irrigation. On the other hand, The irrigation authority is responsible for the supply and should fulfill the requirement to the water users. Therefore, next to those criteria the authority should be focused on the efficiency of the water supply, water saving and resource conservation. Several studies have been made for establishing water and salt balances for the Nile Delta. They followed the approaches; treating the whole Delta as one unit( Zikri et al,1984) and
(Ritjima et al,1984) or dividing the Delta into three regions according to their positions from the Nile branches(Volker, 1979); (Salem et al,1980); (AbuZeid et al,1991). This study presents a new attempt to evaluate the effect of creating work breakdown structure on water and salt balance in the region through dividing the Eastern Nile Delta into two irrigation and drainage systems. Each system contains subsystems and is dealt with separately to produce its water and salt balances.

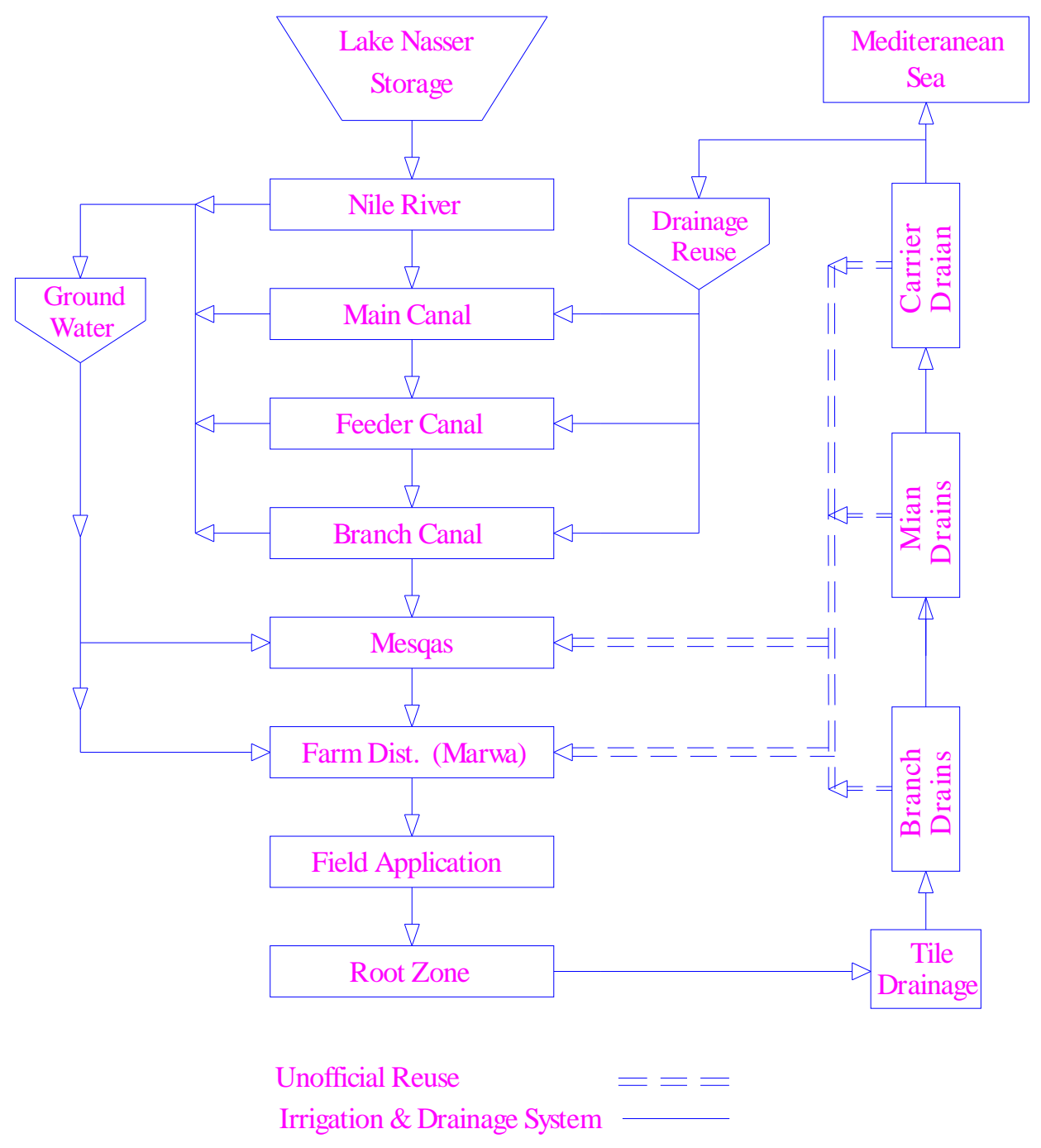

Fig. (1) Irrigation and drainage system 



\section{RESEARCH METHODOLOGY AND MATERIALS}

2-1 Study Area (Eastern Nile Delta Region)

The study area is Eastern Nile Delta Region (ENDR). ENDR boundaries are Manzala Lake from the north, dammitta branch from the west, Suez canal, Morra Lakes from the east and Greater cairo and Eastern Desert from the south.

In this study, ENDR divided into two irrigation and drainage systems. The first one is Manzala Irrigation and Drainage System (MIDS), the second is Ismailia Irrigation and Drainage System(IIDS). MIDS boundaries are Manzala Lake from the north, dammitta branch from the west, IIDS from the east and Greater cairo and IIDS from the south. IIDS boundaries are Manzala Lake from the north, Manzala Lake and MIDS from the west, Suez canal and Morra Lakes from the east and Eastern Desert from the south.

\section{2-1-1 Manzala Irrigation and Drainage System (MIDS)}

Manzala irrigation and drainage system (MIDS) defined as the area served by all the open drains that discharge their drainage water into Manzala Lake, dammitta branch and fed by El Tawfiqi Rayah, El Mansureya, El Salam, El Sharquaweya, El Bassossia and Abo El Meanagga canals. Fig.(2) shows the open drains systems in the Eastern Nile Delta Region.

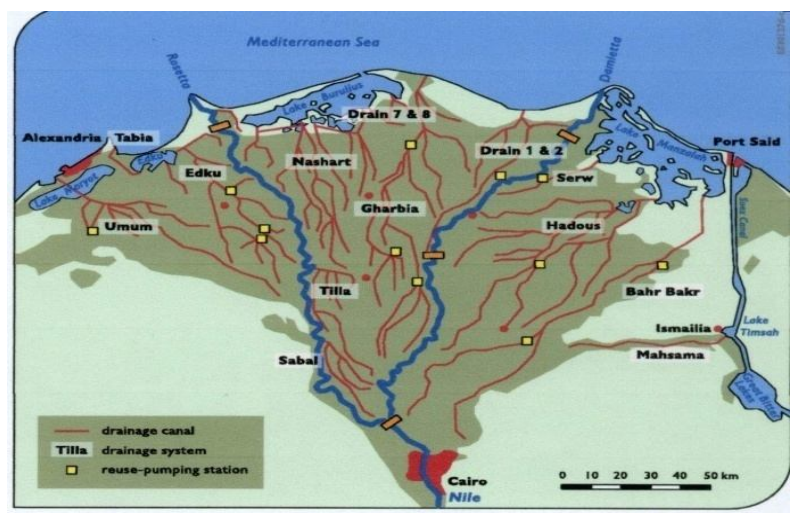

Fig.(2) Open drains systems in Nile Delta

Fig.(3) shows irrigation canal systems in the Eastern Nile Delta Region.

\section{2-1-2 Ismailia Irrigation and Drainage System (IIDS)}

Ismailia irrigation and drainage system (IIDS) consists of the area fed by Ismailia canal and all the open drains served the area fed by Ismailia canal.

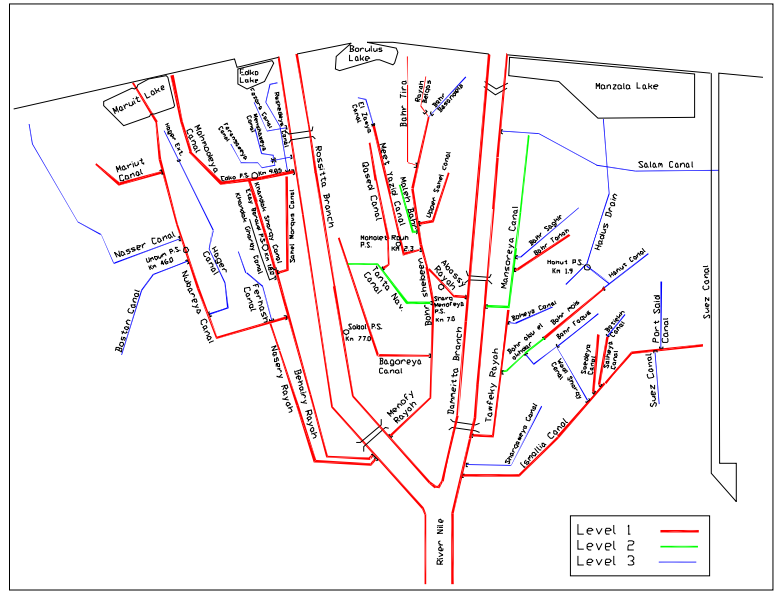

Fig.(3) Irrigation canals systems in Nile Delta

2-2 ENDR Water Quantity and Quality 2-2-1 Water Quantity Program 2-2-1-1 Discharge Measurement at Pumping Stations

The Mechanical and Electrical Department of the MWRI collects the basic data; water levels at suction and delivery sides, number of operating hours, electric power consumption and calculates the total discharge.

\section{2-2-1-2 Discharge Measurement at Open Locations}

For each canal and open drain location, not affected by backwater, a basic stage - discharge relation has been established from calibration measurements. At the locations, where water level recorders are installed, the levels are recorded continuously and regular discharge data can be obtained by irrigation and drainage local authorities. Extra measurements have been done for Bahr El Baqar open drain as a source of irrigation water in the areas passing through.

\section{2-2-2 Water Quality Program}

All the design criteria of the monitoring network to determine sampling location, monitored water quality parameters, sampling frequency, the measurement and laboratory analysis in field and in the laboratory and the description of data evaluation procedures has been provided by irrigation and drainage authorities.

\section{2-3 Caracteristics of Water Quality}

Water and wastewater used in this study was collected from canals, open drains and pump stations monitoring sites as mentioned above. Table (1) shows the physical and chemical proprieties of the water used during this study. 
Table (1): Physical and chemical proprieties of water used during this study

\begin{tabular}{|l||c|}
\hline Parameters & Values (open drains) \\
\hline \hline EC,dS/m & From 5.4 to 0.9 \\
\hline
\end{tabular}

\section{2-4 Measurements Programs}

The measurements programs were carried out in ENDR between (AUG.2000 - JULY2010). Table

(2) represents the measurements used during this study.

\begin{tabular}{|c|c|c|}
\hline Duration & $\begin{array}{c}\text { Water quantity } \\
\text { measured } \\
\text { parameter }\end{array}$ & $\begin{array}{c}\text { Water quality } \\
\text { measured } \\
\text { parameters }\end{array}$ \\
\hline $\begin{array}{l}\text { AUG.2000 } \\
\text { to } \\
\text { JULY2010 }\end{array}$ & Discharge & EC \\
\hline
\end{tabular}

2-5 Laboratory Analysis

Samples analyses were conducted according to the American Standard Methods for the Examination of Water and Wastewater.

\section{2-6 Water Balance Equation}

In this study, the water balance in ENDR into the top part (clay cap) can be expressed by the following equation : $\quad \mathrm{I}=\mathrm{ET}+\mathrm{D}-\mathrm{S}$.....(1)

$\mathrm{I}=$ Total influent water to the system.

$\mathrm{ET}=$ Crop evapotranspiration.

$\mathrm{D}=$ Drainage water to the sea.

$\mathrm{S}=$ Upward brackish water.

In ENDR, As the prevailing irrigation practices proceed from the available source - canals, open drains and wells - whatever the quality of water and there is no changes in ground water levels( DRI and EPADP report, 2007); this study ignored the role of vertical downward seepage. Also, equation 4 ignores the direct evaporation from open water surfaces, changes in soil moisture above the water table and human activities consumptions. The later values may be negligibly small for long time interval(i.e. one year or more).

\section{2-7 Salt Balance Equation in MIDS}

In this study, the water balance in the Eastern Nile Delta Region in the top part ( clay cap ) can be expressed by the following equation:

$$
\mathrm{Ci}=\mathrm{Cd}-\mathrm{Cs}+\Delta \mathrm{z} \ldots . .(2)
$$

Where $\mathrm{Ci}, \mathrm{Cd}$ and $\mathrm{Cs}$ are Salt load in influent, drainage and sea water respectively. $\Delta \mathrm{z}$ is the change in salt storage in the soil,(+) is an increase and (-) is a decrease in storage.

\section{3- Results and Discussion:}

\section{3-1 Water and Salt Balance in ENDR}

\section{3-1-1 Water Balance in ENDR}

Fig.(4) shows the water balance components in eq. 1 determined for Eastern Nile Delta Region (ENDR). Results of ENDR water balance elements; total influent water quantities, effluent drainage water, upward and seawater intrusion flow to drainage system and ET ranged between 1614314389.3, 5453.2-3730.8, 943.5-615.8 and 12551.49882.3 million $\mathrm{m} 3 /$ year respectively. The present results are agreed with the study sponsored by the Planning Sector in MWRI by Drainage Research Centre (DRI, 1993) which stated that" The Nile water quantities, drainage water to the sea, seawater intrusion flowing into the soil and ET for ENDR were 11590, 4054, 924 and 8195 million m3/year respectively". The influent discharges of domestic and industrial water from Greater Cairo into ENDR ranged from 1332.6 to 998.8 million $\mathrm{m} 3 /$ year, represent $9 \%$ to $7 \%$ from the total influent water.

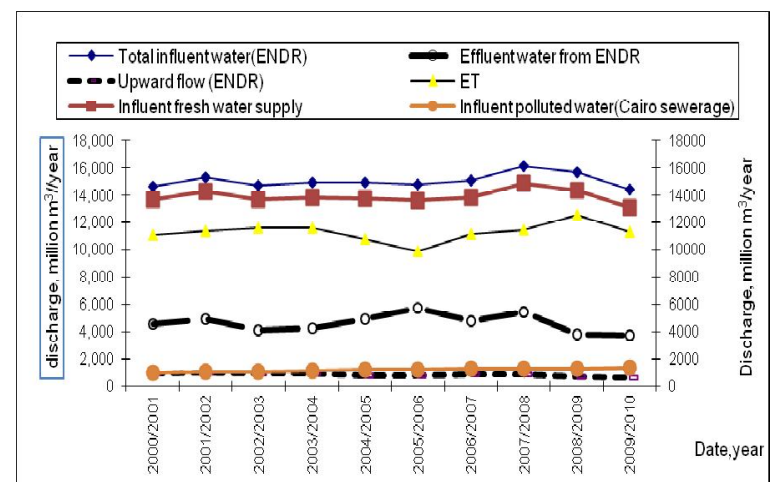

Fig.(4) water balance components determined for ENDR

The influent discharges of domestic and industrial water from Greater Cairo into ENDR gradually increasing may be due to the increase of population and population activities The intruding seawater almost decreasing, the ground water flow to the sea may be pushed the sea water backward as a result of excess quantities of non saline surface water in the upward flow zone. The influent fresh water to 
the system didn't completely follow ET demands, this result may be due to using another source of water in irrigation. The effluent drainage water almost inversely proportional with ET, this may be due to using open drains water in irrigation and fish farming activities.

\section{3-1-2 Salt Balance in ENDR}

Fig.(5) shows the salt balance components in eq. 2 determined for Eastern Nile Delta Region (ENDR). Results of ENDR salt balance elements; salt load in influent water, salt load in drainage water leaves ENDR, salt load in upward and intruding seawater and the change in salt storage in the soils ranged between 5.6-4.4, 9.8-6.7, 9.2-6.9 and 6.6-2.3 million ton/year respectively. The present results are almost agreed with the study sponsored by the Planning Sector in MWRI by Drainage Research Centre (DRI, 1993) which stated that "The salt load in irrigation fresh water, salt load in drainage water leaves ENDR, salt load in the upward and intruding seawater and the change in salt storage in the soils for ENDR were 3.477, 7.297, 32.171 and 28.001 million ton/year respectively.

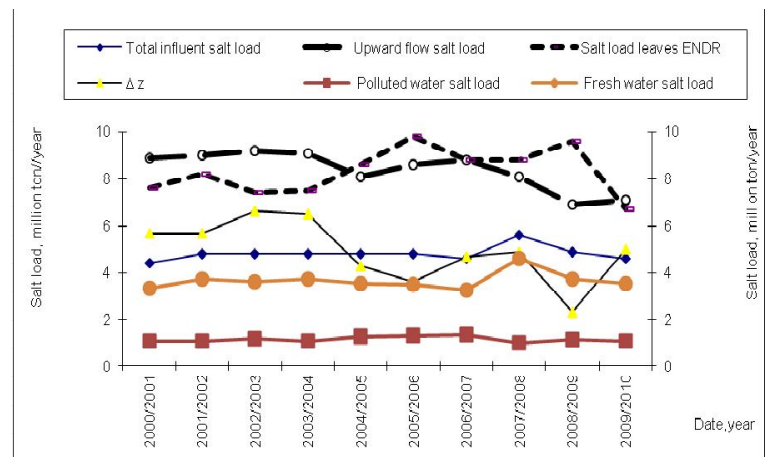

Fig.(5)salt balance components determined for ENDR

The Salt load of the fresh irrigation water ranged from 4.6 to 3.2 million ton/year and depends on the quality and the quantity of the influent water. The salt load from greater Cairo polluted domestic and industrial, ranged from 1.352 to 0.997 million ton/year, depends on the quality and the quantity of the influent water and represent $29 \%$ to $18 \%$ from the total salt load in influent water. The salt load from the upward and intruding seawater almost decreasing, the ground water flow to the sea may be pushed the sea water backward. The most serious source of salts is seawater. The change in salt storage in the soils is inversely proportional with Salt load in drainage water leaves ENDR. The salt balance of ENDR result into adding extra salt loads. Fortunately, the salts which are brought in by the upward and sea water are not spread out over the ENDR region but they remain contained in the upward and seawater wedge at the coastal zone.

\section{3-2 Water and Salt Balance in MIDS}

\section{3-2-1 Water Balance in MIDS}

Fig.(6) shows the water balance components in eq. 1 determined for Manzala Irrigation and Drainage System(MIDS). Results of MIDS water balance elements; influent water quantities, effluent drainage water, upward and seawater intrusion flow to drainage system and ET ranged between 10.4-9, 4-2.1, 0.7-0.4 and 8.5-6.3 billion $\mathrm{m} 3 /$ year respectively. The influent discharges of domestic and industrial water from Greater Cairo ranged from 1.3 to 0.99 billion m3/year and represent $17 \%$ to $11 \%$ from the total influent water.

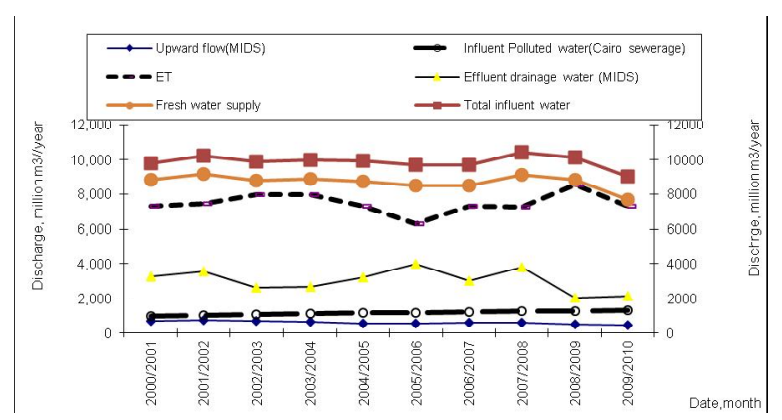

Fig.(6) water balance components determined for MIDS

The influent discharges of domestic and industrial water from Greater Cairo gradually increasing may be due to the increase of population and population activities. The intruding seawater almost decreasing, the ground water flow to the sea may be pushed the sea water backward as a result of excess quantities of non saline surface water in the upward flow zone. The influent fresh water to the system didn't completely follow ET demands, this result may be due to using another source of water in irrigation. The effluent drainage water almost inversely proportional with ET, this may be due to using open drains water in irrigation and fish farming activities.

\section{3-2-2 Salt Balance in MIDS}

Fig.(7) shows the salt balance components in eq. 2 determined for Manzala Irrigation and Drainage System(MIDS). Results of MIDS salt balance elements; salt load in influent water, salt load in effluent water leaves MIDS, salt load in upward 
and intruding seawater and the change in salt storage in the soils ranged between 4.4-3.3, 5.7-3, 7.1-4.9 and 6.8-3 million ton/year respectively. The Salt load of the fresh irrigation water ranged from 3.4 to 2.1 million ton/year and depends on the quality and the quantity of the influent water. The salt load from greater Cairo polluted domestic and industrial, ranged from 1.3 to 0.99 million ton/year, depends on the quality and the quantity of the influent water and represent $37 \%$ to $23 \%$ from the total salt load in influent water. The salt load from

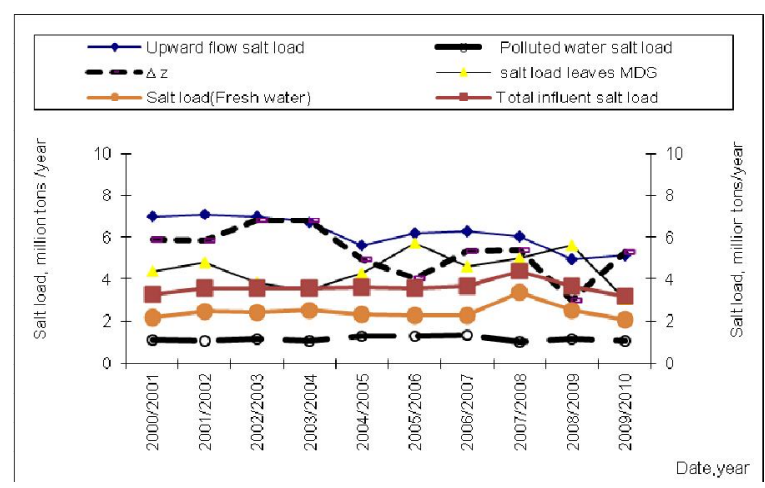

Fig.(7)salt balance components determined for MIDS

The upward and intruding seawater almost decreasing, the ground water flow to the sea may be pushed the sea water backward. The most serious source of salts is seawater. The change in salt storage in the soils is inversely proportional with Salt load in drainage water leaves MIDS . The salt balance of MIDS result into adding extra salt loads. Fortunately, the salts which are brought in by the upward and sea water are not spread out over the MIDS region but they remain contained in the upward and seawater wedge at the coastal zone.

\section{3-3 Water and Salt Balance in IIDS}

\section{3-3-1 Water Balance in IIDS}

Fig.(8) shows the water balance components in eq. 1 determined for Ismailia Irrigation and Drainage System (IIDS). Results of IIDS water balance elements; influent water quantities, effluent drainage water, upward and seawater intrusion flow to drainage system and ET ranged between 5.7-4.8, $1.8-1.3,0.23-0.17$ and 4.2-3.5 billion $\mathrm{m} 3 /$ year respectively. The upward flow and the intruding seawater almost decreasing, the ground water flow to the sea may be pushed the sea water backward as a result of excess quantities of non saline surface water in the upward flow zone. The influent fresh water to the system followed ET demands. The effluent drainage water almost increasing, following the influent fresh water to the system.

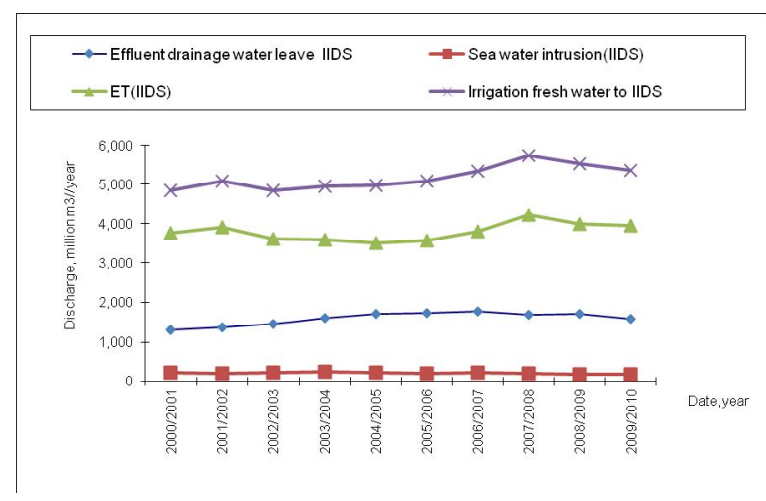

Fig.(8) water balance components determined for IIDS

\section{3-3-2 Salt Balance in IIDS}

Fig.(9) shows the salt balance components in eq. 2 determined for Ismailia Irrigation and Drainage System (IIDS). Results of IIDS water balance elements; salt load in influent water, salt load in drainage water flow to the sea, salt load in the ithe soils ranged between 1.4-0.99, 4.3-3.3, 2.5-1.9 and 0.7- - 0.17 million ton/year respectively. The resulting Salt load of the fresh irrigation water depends on the quality and the quantity of the influent water. The most serious source of salts is seawater. The change in salt storage in the soils is inversely proportional with Salt load in drainage

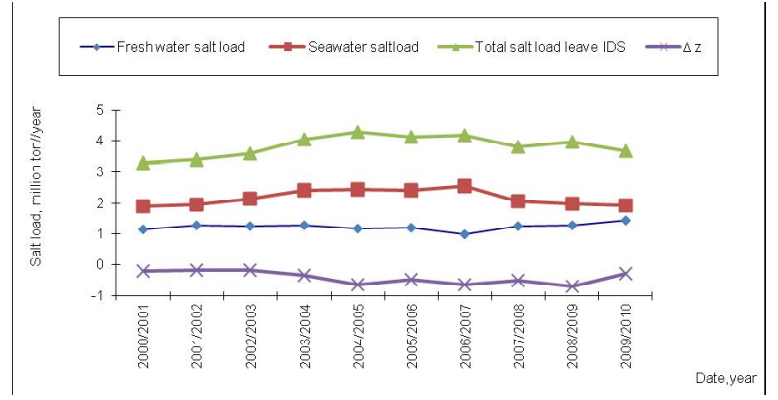

Fig.(9)salt balance components determined for IIDS

water flow to the sea. The salt load in drainage water flow to the sea almost followed the salt load from the upward and intruding seawater. IIDS salt balance results showed leaching salt from soil. 


\section{3-4 Influent Water Supply Quantities}

Fig.10 shows the influent water quantities to ENDR, MIDS and IIDS. IIDS fresh water supply quantities, which are at the same time the total water supply quantity, were 4852.7and 5359.7 million m3/year at year 2000/2001 and year $2009 / 2010$ respectively. The average fresh water supply was 5174.4 million m3/year. During the study time(Aug.2000 to july2010), IIDS fresh water supply quantities almost gradually increasing, this may be due to the fresh water demand increasing.

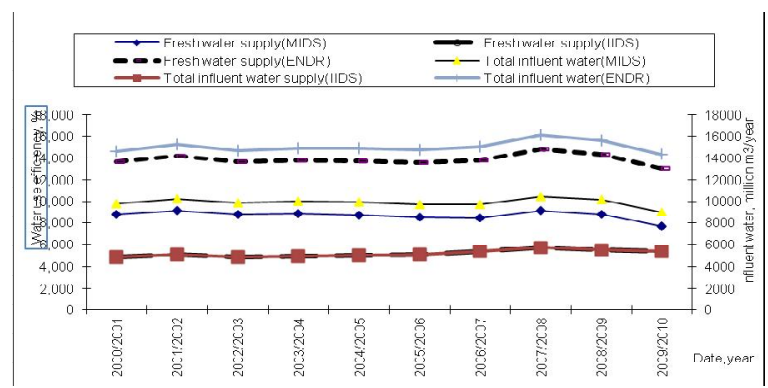

Fig.10 the influent water quantities to ENDR, MIDS and le IIDS

MIDS total influent water supply quantities, which consists of fresh water supply and greater Cairo polluted domestic and industrial water, were 9820.7 and 9029.6 million m3/year at year2000/2001 and year 2009/2010 respectively. The average total influent water supply was 9889 million m3/year. During the study time(Aug.2000 to july2010), MIDS total influent water quantities almost constant although the ET water demands are increasing. MIDS fresh water supply quantities were 8821.9 and 7696.9 million m3/year at year $2000 / 2001$ and year 2009/2010 respectively. The average fresh water supply was 8710 million m3/year During the study time(Aug.2000 to july2010), MIDS fresh water supply quantities almost decreasing although the ET water demands are increasing, this may be due to the intention to subjugate greater Cairo polluted domestic and industrial water to the irrigation system. ENDR total influent water supply quantities, which consists of fresh water supply and greater Cairo polluted domestic and industrial water, were 14673.4 and 14389.3 million m3/year at year2000/2001 and year 2009/2010 respectively. The average total influent water supply was 15063 million m3/year. ENDR total influent water quantities almost constant during the study time although the ET water demands are increasing. Also, ENDR fresh water supply were 13674.7 and
13056.6 million m3/year at year 2000/2001 and year 2009/2010 respectively. The average fresh water supply was 13885 million m3/year. ENDR fresh water quantities almost constant during the study time although the ET water demands are increasing this may be due to the intention to subjugate greater Cairo polluted domestic and industrial water to the irrigation system.

\section{3-5 Irrigation Rates}

Fig.11 shows the irrigation supply rates in ENDR, MIDS and IIDS. Up to the year 2003-2004 the irrigation supply rates almost corresponding. From the year 2004/2005, IIDS showed remarkable increment in irrigation supply rates at variance of MIDS which showed remarkable decrease. ENDR irrigation supply rates ranges from 4.3 to 3.8 $\mathrm{mm} /$ day. MIDS irrigation supply rates ranges from

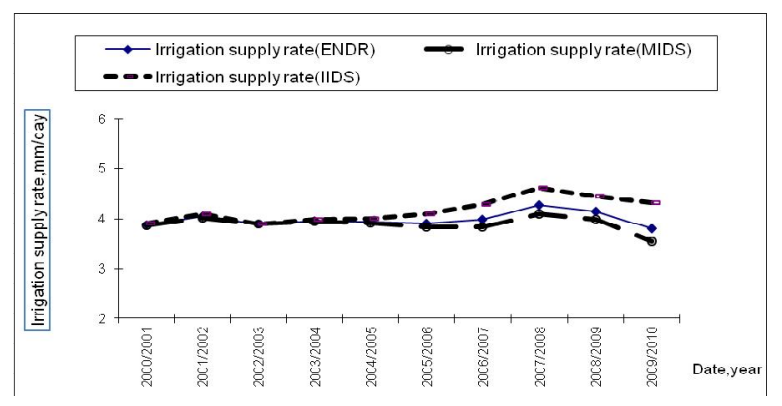

Fig.11 Irrigation supply rates in ENDR, MIDS and IIDS.

4.1 to $3.6 \mathrm{~mm} /$ day. IIDS irrigation supply rates ranges from 4.6 to $3.9 \mathrm{~mm} /$ day. The present results are agreed with the study sponsored by the Planning Sector in MWRI by Drainage Research Centre (DRI, 1993) which stated that "The average drainage rate over the whole Delta during the period 1984/1990 is about $1.8 \mathrm{~mm} /$ day. Recalling that the average annual supply of the Nile water to the Delta during the same period is about 34.6 billion m3/year, then the supply rate per unit area would be $4.8 \mathrm{~mm} /$ day".Also, The present results are agreed with (Volker, 1979) who stated that the delivery rate for Eastern Delta is 5.0 $\mathrm{mm} /$ day.

\section{3-6 Water Use Efficiency}

Fig.12 shows water use efficiency in ENDR,MIDS and IIDS.IIDS results showed fairly stable narrow range water use efficiency ranged from $78 \%$ to $70 \%$, but ENDR affected by MIDS, both water balances results showed unstable wider range water use efficiency ranged from $80 \%$ to $\% 67$ and $84 \%$ to $65 \%$ respectively. The present results are agreed with the study sponsored by the Planning Sector in 
MWRI by Drainage Research Centre (DRI, 1993) which stated that "The overall water use efficiency over the whole Delta can be estimated as $62 \%$ during the period 1984/1990. It should be noted that the calculated efficiency is under estimated as the drainage water includes a portion which is either originated from the sea water or deep artesian groundwater.

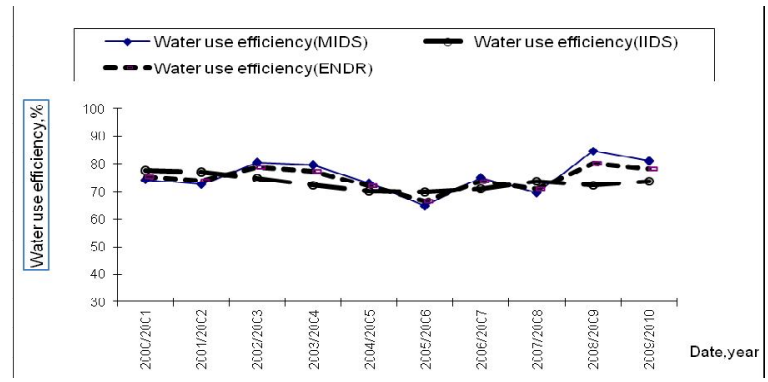

Fig.12 water use efficiency in ENDR,MIDS AND IIDS

\section{Conclusion}

The smaller are the area, the more accurate are the water and salt balance evaluations. This results comply with (PMBOK GUIDE, 2008) which stated that "Create Work Breakdown Structure is the process of subdividing project deliverables and project work into smaller, more manageable components". The research work in this study execute a water and salt balance in Eastern Nile Delta Region (ENDR). Dividing ENDR into Manzala and Ismailia Irrigation and Drainage Systems; MIDS and IIDS. Results of water balance elements; total influent water quantities, effluent drainage water, upward and seawater intrusion flow to drainage system and ET for ENDR ranged between 16.1-14.4, 5.5-3.7, 0.94-0.62 and 12.6-9.9 billion m3/year respectively, for MIDS ranged between 10.4-9, 4-2.1, 0.7-0.4 and 8.5-6.3 billion m3/year respectively and for IIDS ranged between5.7-4.8, 1.8-1.3, 0.23-0.17and 4.23.5 billion m3/year respectively. Results of salt balance elements; salt load in influent water, salt load in drainage water flow to the sea, salt load in the intruding seawater and the change in salt storage in the soils for ENDR ranged between 5.64.4, 9.8-6.7, 9.2-6.9 and 6.6-2.3 million ton/year respectively, for MIDS ranged between 4.4-3.24, 5.7-3, 7.9-4.9 and 6.8-3 million ton/year respectively and for IIDS ranged between 1.4-0.99, 4.3-3.3, 2.5-1.9 and-0.7- -0.17 million ton/year respectively. Division showed better and stable water management policies in IIDS with water supply followed ET demands, fairly stable narrow range water use efficiency ranged from $78 \%$ to 70 $\%$ and salt leaching process. At the contrary, ENDR affected by MIDS, both water balances results showed poor follow of ET demands by water supply, wider range of water use efficiency ranged from $80 \%$ to $67 \%$ and from $84 \%$ to $65 \%$ respectively and adding extra salt loads process in the salt balance boundaries.

\section{REFERENCES}

1- Abu-Zeid, M. and Abdel- Dayem, M., 1991. Variations and Trends in Agricultural Drainage Water-use in Egypt. VIIth World Congress on Water Resources, IWRA, 13-18 May, Rabat, Morocco.

2- DRI, 1993. Drainage Water, A Study Sponsored by the Planning Sector in MWRI, Water Security Project,V2, by Drainage Research Centre, Drainage Water Status In Nile Delta.

3- Khorshed, A.M (2010) ; Effect of open drains hydraulic cross sections changes on the quality of water passing through it. M.Sc Thesis, Fac. Eng. Zagazig.

4- PMBOK GUIDE, 2008. Project Management Institute, Global Standard, Project Management body of Knowledge, Forth Edition.

5- Rijtema P.E. , 1984.Water and Salt Balance Approach. Proceedings of Workshop on Reuse of Drainage Water, Cairo.

6- Rijtema P.E. and Roest, C.W.J.,1982. Re-use of Drainage Water II. Data Analysis Panel Report 82.XI.02. Advisory Panel for Land Drainage in Egypt.

7- Volker, A.1979. Re-use of Drainage Water, Programme of Systematic Investigations. Panel Report 80.III.01. Advisory Panel for Land Drainage in Egypt.

8- Volker, A.1979. Re-use of Drainage Water Measurement and Inventory. Panel Report 80.VI. Advisory Panel for Land Drainage in Egypt.

9- Zikri B., et al, 1984.Water and Salt Balance of the Nile Delta Area. Proceeding of Workshop on Re-use of Drainage Water,Cairo. 